\section{¿Quién es Susana? \\ La representación del mal preterna- tural y terrenal en una película de Luis Buñuel}

Who Is Susana?

The Representation of Natural and Preternatural Evil in a Film by Luis Buñuel

Alberto Ortiz

albor2002@gmail.com

https://orcid.org/0000-0001-6495-221X

Universidad Autónoma de Zacatecas, México.

FECHA DE RECEPCIÓN diciembre 24, 2019

FeCHA DE APROBACIÓN mayo 19,2020

FeCHA de PUBLICACIÓN julio 1, 2020

https://doi.org/10.32870/ elojoquepiensa.v0i2 1.345
Resumen / La película Susana muestra los prejuicios e ideas tradicionales respecto a las funciones de las mujeres. Por medio de un contraste entre personajes opuestos, la trama cuestiona la identidad masculina y la validez de los esquemas morales que prevalecían en la sociedad mexicana del siglo XX. Sin embargo, el personaje principal es una incógnita constante, pues se desconoce quién es Susana y por qué actúa a manera de un agente maligno, lo cual da pie a remitir sus acciones al mal infernal, aunque solo se trate de una manifestación de la conducta humana.

Palabras clave / mujer, maldad, moral.
A Bstract / The film Susana shows prejudices and traditional ideas regarding the roles of women. Through a contrast between opposing characters, the plot questions the male identity and the validity of the moral patterns that prevailed in Mexican society of the twentieth century. However, the main character is a constant mystery, since it is unknown who Susana is and why she acts in the manner of an evil agent, which leads to refer her actions to hellish evil, even if it is only a manifestation of the human behavior.

KEYWORDS / woman, evil, moral. 

El resultado de esta combinación de artistas y escritores es una obra singular, especialmente inquietante y útil para dirimir las características de la malignidad operando entre los hombres comunes. Esta arista resalta, a pesar de que la crítica global no le ha favorecido del todo, pues algunos críticos consideran que es demasiado melodramática, comercial y realista; el propio Buñuel prefirió no abundar en sus apreciaciones al respecto y hay quien señala que "Susana es una película claramente dirigida al público más popular, a los consumidores del cine de géneros menos sofisticado" (Losilla, 1995, p. 23).

Esta película no es la única que parece despertar los resquemores de los críticos e historiadores a la hora de calificar los productos de la época. El recelo no es gratuito. Resulta evidente que hay notables diferencias entre la producción buñueliana en México y la deslumbrante producción de su etapa previa, meramente europea y surrealista. Salvo Los olvidados (1950), el resto de sus éxitos en México forman parte de eso, de una intención comercial y taquillera para darle gusto, como afirma la cita anterior, al público en general. Lo cual no deja de ser un problema y un reto al mismo tiempo, es decir, constituye un dilema para el creador, ante el cual hay que adaptarse o rebelarse subrepticiamente, dada la imposibilidad de la renuncia total. En palabras de Sara Díez:

La censura institucional, la pobreza de medios técnicos, la premura de los rodajes, los argumentos mediocres, los géneros estereotipados de la industria mexicana - con el melodrama a la cabeza - así como la imposición de guiones y actores sirvieron al realizador aragonés de acicate a su imaginación creadora. Así, el sometimiento a las normas del lenguaje narrativo clásico fue solo aparente. Su debut con Gran Casino (1947) y otras películas alimenticias - con las cuales se garantizaba la subsistencia-, le sirvió de toma de contacto para adaptarse y conocer el método mexicano (Díez Ortiz de Uriarte, 2010, pp. 146-147).

Es decir, si el talento de todo artista se distingue y define cuando trasciende naturalmente los moldes, Luis Buñuel, al menos en algunos detalles durante esa etapa de producción convencional en México, logró poner en crisis al modelo melodramático de las cintas comerciales y cuestionó la realidad circundante incluso ahí donde el más puro convencionalismo moral se instalaba con toda su rigidez religiosa y social. Lo demuestran, en la obra aquí analizada, la escena introductoria de la celda, el resquebrajamiento de la voluntad patriarcal, los gestos eróticos sorprendentemente reveladores, acaso solapados y, especialmente, de acuerdo al rubro que nos inquieta y ocupa aquí, la representación de la malignidad femenina y/o feminización de la malignidad ${ }^{2}$.

Aunque el tratamiento del mal en el arte conlleva aspectos culturales complejos y difíciles de explicar, los rasgos de la malignidad, demoniaca y humana, dispuestos en esta trama, pueden describirse develando la identidad del personaje principal. Una duda que persiste a lo largo de la historia y que nunca termina por responderse con profusión o claridad: ¿quién es Susana?

El presente trabajo intenta dilucidar esta cuestión por medio de un sencillo ejercicio hermenéutico; a saber, proponiendo las preguntas esenciales al texto cinematográfico respecto de la identidad del personaje y respondiendo de acuerdo a los parámetros de la tradición discursiva alrededor de la magia, la demonología y las supersticiones.

Para el espectador promedio, casi desde el inicio de la película, parece claro que la joven extraña será el personaje malvado de la trama, así que, naturalmente, espera una serie de acciones que confirmen su percepción. La historia no le decepcionará. Algunas de las más protervas actitudes de la maldad se pondrán en juego y conducirán a ciertas crisis emocionales a aquellos otros personajes considerados inocentes, o no tan malos como ella. No obstante, la duda persistirá, no hay certeza del origen del mal, no se sabe por qué el personaje femenino actúa de esa manera y contamina un

${ }^{2}$ Otro tanto puede discutirse analizando la recreación hagiográfica dispuesta en la película inconclusa, o al menos abruptamente recortada, Simón del desierto (1965), en donde Buñuel inserta un perturbador demonio femenino representado por la actriz Silvia Pinal. Este caso no se incluye aquí porque formará parte de una reflexión posterior. 
ambiente antes calmo y tradicional de acuerdo a los dibujos comunes que la cinematografía nacional ha hecho del medio rural mexicano. La explicación de la presencia del mal fluctúa entre la iniquidad humana y la malignidad preternatural. Ciertamente no se trata de un drama fantástico, no aparecen personajes mitológicos, como demonios o brujas, pero, mediante símbolos, connotaciones y sugerencias, al menos parte de la interpretación de los defectos morales que se desarrollan se remite a la intervención y contigüidad diabólicas a través de una representación de la mujer considerada réproba y transgresora. Factores ideológicos que la mayor parte de los estratos sociales del México conservador, urbano y rural, de mitad del siglo XX, depositaban en las identidades femeninas, especialmente en aquellas que reunían indicios conductuales diferentes o contrarios a los convencionalismos y formas de vida normados por la moral pública civil, heredera de la doctrina católica, regidora social omnipresente, a pesar del avance moderno, que exigía en las mujeres personalidades humildes, sinceras y abnegadas, mientras que criticaba su falta de palabra, entereza y veracidad. En muchos sentidos, el país y la comunidad que la película de Buñel retrata corresponde a lo que Ricoeur llama "la diferenciación de los órdenes de verdad", ya que la realidad aprendida y la norma ético-religiosa marcan en el sujeto común la noción de verdad con la cual se juzga a los demás: "La síntesis clerical de lo verdadero es culpa de la autoridad especial que el creyente concede a la verdad revelada, lo mismo que la síntesis política de lo verdadero es culpa de la política cuando pervierte su función natural y auténticamente dominante en nuestra existencia histórica" (Ricoeur, 1990, p. 146).

Desde este contexto teórico es fácil entender por qué la película cierra sus diálogos y el microcosmos del drama mismo, al tiempo que cierra una ventana, remarcando a la realidad como "la pura verdad de Dios".

La versión más completa acerca de la identidad de Susana es expresada por el propio personaje cuando - ya confortada por los cuidados de Carmen ${ }^{3}$, la señora de la casa, quien la interroga - declara que su nombre es simplemente Susana ${ }^{4}$, no tiene apellidos, es huérfana, no conoció a sus padres, fue recogida por una mujer, el marido muere y la nueva pareja de su tutora la trataba mal e insistía en mancillarla, el sujeto la sacó de su casa para que trabajara y en el camino intentó violarla, ella escapó y llegó hasta la hacienda. Sin embargo, está claro que miente. El lenguaje corporal, la inflexión de sus frases, la exageración de sus agradecimientos y la desconfianza de Felisa ${ }^{5}$, la criada principal, la delatan. En realidad, la trama da apertura a la detección de sus mentiras, el público está enterado de la verdad por medio de la primera escena, ha escapado de un reformatorio estatal y ahora se esconde de las autoridades. Tales antecedentes no esclarecen la duda de su origen e identidad, al contrario, la extracción del asilo la destina al anonimato. El jefe de la hacienda, don Guada-

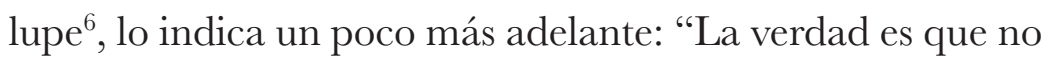
sabemos quién es, ni de dónde viene"

¿Es Susana el mismo Lucifer? Según Felisa, supersticiosa y crédula, así es, al menos para ella lo representa fehacientemente. La presencia luciferina acaece a fin de iniciar el caos, la discordia, el pecado; la inusual tormenta, torrencial, llena de

${ }^{3}$ Papel interpretado por Matilde Palou, actriz chilena de teatro, de cine y de doblaje. El famoso pintor Diego Rivera le hizo un retrato.

${ }^{4} \mathrm{El}$ personaje fue interpretado por Rosita Quintana, cantante y actriz de origen argentino, nacionalizada mexicana, gloria viva del cine nacional, artista multifacética que participó en más de cincuenta filmaciones. Buñuel aprovechó su natural sensualidad y belleza para encarnar esta variante de mujer malvada.

${ }^{5} \mathrm{El}$ papel fue interpretado por la valenciana María Gentil Arcos. Hermana de las también actrices Natalia y Conchita Gentil Arcos. Pilares de la figura femenina de la Época de Oro, destacaron más María y Conchita.

${ }^{6} \mathrm{El}$ personaje lo encarnó don Fernando Soler, de la dinastía Soler que tanto lustro dio al teatro y cine nacional. Como en el resto de sus actuaciones, este papel es muestra del realismo, credibilidad, reposo, dominio y control que dotaba a cada uno de sus personajes.

${ }^{7}$ Todas las citas textuales incluidas en este trabajo están tomadas de los parlamentos de la película en cuestión, transcribiendo las palabras enunciadas por los personajes a escritura. 
rayos y truenos, en medio de las tinieblas, augura la cercanía del diablo: "(...) y cuando viene una tormenta así, es cosa del demonio". Afirma la vieja sirvienta, justo en la primera escena al interior de la casa grande de la hacienda. Más adelante, cuando el estruendo de un rayo rompe la vajilla, ella vuelve a anunciar asustada y quejumbrosa: "QQué se me hace que anda suelto el diablo por ahí!, con perdón de la Santísima Trinidad”, mientras se santigua por enésima vez. En ese momento aparece Susana tras la ventana, entre la lluvia, como una aparición fantasmal, asustando a doña Carmen, quien se santigua también y la señala. Felisa reafirma su percepción agorera: “¡Ay, niña! ¡Es el diablo! Como dice el señor cura: ¡Vade resto, Satanás! ${ }^{8 ”}$. Más adelante, en medio de la crisis que su presencia y acciones provocan, Carmen confiesa a su criada el impulso que tuvo de matarla, a lo que ella responde: "Ya sabía yo que era el demonio el que nos iba a embrujar a todos, jéchela!’. Por último, cuando llega el final, exclama con un dejo de victoria y satisfacción: “¡Bien dije yo que esa mujer era el demonio!”. La escena que cierra el drama asemeja el arrastre de las almas malditas hacia el infierno, Susana, en función de demonio, es devuelta al agujero condenatorio de donde salió.

Resulta evidente que Felisa es la vocera de la tradición supersticiosa. Sus parlamentos refieren las creencias vulgares respecto a los peligros de la presencia del mal diabólico entre los hombres. Proclama malos augurios, intuye demonios cercanos, traduce el evento como un atentado infernal. Ella revela que la inserción de la mujer sensual al seno de la familia rural, tradicional, patriarcal y de moral férrea, solo puede acarrear el resquebrajamiento de esa realidad que se considera sólida, incluso buena y correcta de acuerdo a las normas religiosas, pero que, paradójicamente, sin que la trama lo perciba o plantee intencionalmente, está tan expuesta a las tentaciones externas, especialmente si son eróticas, que devela una

${ }^{8}$ Felisa es un personaje ignorante, supersticioso, una mujer de campo sin instrucción, así que pronuncia mal algunas frases y palabras que escapan a su léxico básico. En este caso la frase es su versión a la fórmula exorcizante tradicional Vade retro, Satana. seria debilidad, pues los líderes de esa rutina se dejan seducir fácilmente por una forastera agente de la maldad, peligrosa sí, pero no invencible. Si sus valores se restablecen se debe más al azar y a la búsqueda de la justificación moral que a la fuerza de la fe y la convicción de los personajes masculinos.

Por su parte, la jefa de familia, obnubilada por su propia bondad, yerra en la calificación del peligro. Ni siquiera lo percibe. Sus creencias no le permiten detectar la amenaza sino hasta que llega el clímax decisivo. De tal manera que la única conciencia que permanece inalterable, y que no comete equivocaciones en sus más íntimas percepciones respecto al mal, es la de la criada Felisa, a pesar de que sus percepciones provengan de las creencias mágicas y estén matizadas de ignorancia supersticiosa.

¿Es Susana el demonio de la lujuria? Su insistencia en usar la lozanía del cuerpo como un arma parece indicar que sí. Luego de pasar por un episodio de voyerismo en el que Susana fuerza las reglas del erotismo e intencionalmente trata de excitar el ánimo del patrón de la hacienda ${ }^{9}$, este pide a su esposa que la vista con recato, no de modo llamativo que supuestamente la premura impuso. Al finalizar de cambiarle la vestimenta, Felisa, la vieja criada, le dice a la patrona: “¡Ay, niña! Me late que esa no se vería recatada ni con un hábito de carmelita!" Y tiene razón. Si la presencia de la mujer joven causó conmoción y deseo incipiente entre los varones del lugar - pues al entrar por primera vez en la casa grande yace sobre el sofá, calada hasta los huesos, embadurnada de lodo, con la ropa húmeda ceñida a su piel y mostrando las piernas mientras es reanimada-, su intención sensual, revelada por el reiterado y subrepticio reacomodo de la blusa hasta los hombros, apenas una pulgada arriba de sus pechos turgentes,

${ }^{9}$ Estas escenas, el dilema erótico, más la evocación del nombre "Susana", llevan a Lincoln Strange Reséndiz (2019) a resaltar una relación entre el personaje del filme y el personaje bíblico, en especial con el pasaje de espionaje en el baño e intento de seducción de la doncella. Por cierto, la imagen ha estado presente en la historia del arte. Es comúnmente conocida como "Susana y los viejos" y fue plasmada por Tintoretto y Rembrandt, entre otros maestros. 
se trasluce incluso enfundada en un vestido más formal, pues su exuberancia se impone sobre cualquier convencionalismo de recato.

Susana irrumpe con su presencia e inmediatamente destaca entre el ambiente conservador de los habitantes de la hacienda. Lo logra mediante una entrada triunfal y fantasmagórica, plena de erotismo. Parece una mujer desvalida que requiere de atención y cariño, pero de inmediato su belleza física provoca conflictos. Primero, Jesús ${ }^{10}$, el capataz de la hacienda, cautivo de sus encantos desde su llegada nocturna entre la tormenta, la defiende de los requiebros y piropos de los peones; enseguida, él mismo declara su gusto. Después, el hijo del patrón, de apariencia intelectual e inocente, cae enamorado sobre sus brazos. Luego es el propio jefe de familia quien sucumbe ante sus encantos, hasta perder su natural mesura, apego a la decencia y conducta dura pero respetuosa.

El uso del erotismo sugiere un riesgo para la dirección. Anteponiendo algunos prejuicios y percepciones sociales comunes durante la época de su difusión, la película parece transgresora. Presenta secuencias cuyo eje narrativo revela eminencia erótica: tres hombres de diferentes edades y capacidades pierden el control de sus actos y rompen los preceptos de la sana convivencia, independientemente de su personalidad y lo férreos que sean sus principios morales. Hay al menos una escena de acercamiento sensual con cada uno de ellos. El motivo es el cuerpo de la joven extraña. Si bien el capataz consigue una parcial posesión y, en ese acto, puede considerarse el ganador del trofeo, los tres reflejan una honda perturbación de los sentidos gracias al erotismo intencional y artificial de Susana, quien, a sabiendas de los efectos, utiliza ambos factores: su belleza física para erotizar y la inercia magnética que los hombres siguen al ver su cuerpo.

¿Es Susana un demonio de la discordia? Si no demonio al menos es, con toda seguridad, manzana de discordia. Ella

\footnotetext{
${ }^{10} \mathrm{El}$ papel fue interpretado por Víctor Manuel Mendoza. Actor jalisciense descubierto por Lina Boytler, esposa del productor Arcady Boytler.
}

ocasiona sentimientos y pareceres encontrados. La primera inconforme con el hospedaje y protección que el ama de casa le dispensa es Felisa. La criada se ve obligada a aceptar la presencia intrusa a pesar de sus resquemores, lo hace para no contradecir a su patrona, pero afirma que si por ella fuera la situación sería diferente. Su animadversión hacia Susana no choca con la generosidad de Carmen, porque ella está acostumbrada a obedecer y acata las órdenes de sus patrones. Pero sí inaugura una batalla de palabras y quejas entre extraña y sirvienta, batalla que perdurará al transcurso de la historia.

Susana muestra ser provocadora de discordia al coquetear con Alberto $^{11}$, el unigénito de los hacendados y permitir los avances de Jesús, el capataz donjuanesco. Entre ellos se desarrolla una enemistad peligrosa, uno pide respeto a su hombría y el otro fidelidad y obediencia en el trabajo. Los celos de ambos ocasionan momentos tensos que caminan hacia la tragedia. Sin embargo, la confrontación entre los jóvenes no llega a la violencia física, porque la discordia principal nace y crece entre padre e hijo. La estrategia erótica de Susana atrapa al padre mientras se divierte con el hijo. Esa pelea con tintes filicidas se extiende a la madre y esposa, quien, a su vez, en el clímax, enfrenta a Susana e intenta castigarla con un escarmiento violento y extático.

En estas ondulaciones de emociones, una alta cresta de discordia aparece, se tensa y casi rompe el esquema de vida normal de la hacienda para siempre. El ama y el patrón enfrentan el peso de su poder frente al resto de los habitantes. Como el sistema favorece al hombre, pues él es el pater familias, el patriarca, la balanza se inclina a su favor; empero, está claro que la semilla de la discrepancia ha sido sembrada entre ellos y que puede tener graves consecuencias. Como se sugiere en la historia, uno de ellos, obviamente doña Carmen, la más débil de los dos, debe perder su estatus y salir del contexto, en medio de la vergüenza y el oprobio. Acontecimiento que está

\footnotetext{
${ }^{11}$ Papel interpretado por Luis López Somoza, quien también actuó en el reparto de la película Aventurera (Alberto Gout, 1950).
} 
a punto de provocarse, a instancias del personaje malvado ayudado por la perturbación erótica del hacendado, cuando llega el desenlace regenerador.

Una cresta menor, casi insignificante pero significativa, muestra la capacidad del personaje para introducir conflicto en la cotidianidad. Cuando Susana pasa frente a los peones, estos la requiebran y molestan un poco. El capataz, a quien tienen por hombre cabal y trabajador, los riñe de fea y exagerada manera, ya perturbado por la idea de poseerla. Finalmente, está claro que ella misma es una alteración del orden, una intrusa cuya inserción en el contexto ajeno provoca inquietud y genera nuevas circunstancias de animadversión.

¿Es Susana una bruja? Si atendemos a su caracterización, misma que la tradición discursiva contra la magia ha instalado en el imaginario colectivo en contraste con el personaje y las referencias que pudieran aparecer en el filme, todo indica que no, puesto que no realiza hechizos, rituales, conjuros o maleficios propios de la brujería; empero, la película sugiere aspectos que la vinculan con la mitología que compone el discurso brujeril: el comportamiento rebelde y violento, la coexistencia con alimañas, su engañosa y seductora belleza, la tormenta inusitada y fuerte en medio de la cual aparece, la referencia a la agresividad de la gata doméstica, supuestamente mansa, que rasguña a la criada, la muerte del potrillo debido a que la mejor yegua de la hacienda mal pare y enferma, cuando toda la gestación iba bien, la sugerencia de una posible plaga acabando con las plantas de maíz, su habilidad para fascinar con la mirada, la atracción sexual que ejerce sobre los hombres y la predicha discordia familiar iniciada a partir de su presencia. A lo que se suma la imagen estereotipada de la bruja o hechicera sensual: joven, hermosa, de larga cabellera suelta, actitud libertina y disposición a la desnudez, una de las muchas caracterizaciones y clichés que el cine ha fortalecido a través del tiempo y que puede ser constatable en hitos que van de El maravilloso mago de $\boldsymbol{O z}$ (The Wonderful Wizard of $O z$, Otis Turner, 1910), pasando por Dies Irae (Carl Theodor Dreyer, 1943) y Las brujas (The Witches, Cyril Frankel, 1966), hasta Maléfica (Maleficent, Robert Stromberg, 2014) y otras recreaciones de nuestros días.

Parte de los síntomas que el mito ${ }^{12}$ señala para identificar la presencia soterrada de la bruja consiste, justamente, en que toda la vida a su alrededor, que antes funcionaba con normalidad rutinaria, empieza a deteriorarse, surgen conflictos, enfermedades, muertes, y un malestar general inexplicable. La presencia de Susana ocasiona una crisis, su presencia altera la normalidad cotidiana, la quebranta, aspecto que puede perfilar y denunciar su identidad diabólica. Desde este enfoque, tendría mucho sentido analizar al personaje de Susana en tanto bruja especial, considerando la hipótesis de que pudiera tratarse de una faceta peculiar, aunque imprecisa, de esta mujer maligna que tantas variantes ha tenido en la historia de la cinematografia; tal como se analizado por algunos especialistas del trinomio mujer-brujería-cine (Zamora Calvo, 2016).

Por otro lado, la imagen, el carácter y las acciones escenificadas por Quintana necesariamente se ligan a la precepción prejuiciada del conservadurismo misógino acerca de las mujeres denominadas "libertinas", "huilas", "cabronas"; las cuales, además, son calificadas de "brujas", no porque lo sean, sino porque el calificativo pretende ofenderlas y reprimirlas para que su ejemplo no cunda entre aquellas que cumplen con las funciones tradicionales respecto al comportamiento de la mujer. En el caso de esta película, el modelo ideal está representado por doña Carmen y la versión brujeril por Susana. La lógica narrativa exige que ambas representen estereotipos opuestos y, en un momento dado, se enfrenten

\footnotetext{
${ }^{12}$ Basado en el discurso erudito contra la brujería. El mito de la brujería está compuesto por variados y sorprendentes episodios, entre los que destacan el vuelo nocturno, las asambleas de brujos o aquelarres, las posesiones diabólicas y el pacto con el diablo. Fue construido desde al poder y tiene una importancia crucial para entender el pensamiento que originó fenómenos como la cacería de brujas. La lista de obras que lo sustentaron es amplísima. Además del Malleus maleficarum (1486), referente de muchos otros textos, sobresalen las obras de Jean Bodin: De magorum daemonomania (1581); Martín del Río: Disquisitionum magicarum (1600); Francisco Torreblanca: Epitomes delictorum in quibus aperta, vel occulta invocatio daemonis intervenit (1618); Gaspar Navarro: Tribunal de superstición ladina, explorador del saber, astucia y poder del demonio (1631); y Johann Wier: De praestigiis daemonum et incantationibus ac veneficiis (1660).
} 
para definir cuál de ellos, el "bueno", la señora, o el "malo", la bruja intrusa, prevalece.

Susana es personaje femenino que sale de los estándares. En la película, encontramos esa imagen de la mujer seductora, muchas veces mostrada en la cinematografía nacional (...) Asimismo, vemos la imagen de la madre abnegada encarnada en doña Carmen (Matilde Palou), una mujer que lucha por salvar a su familia de la tragedia y arrojar fuera de su casa al "demonio", Susana, quien ha seducido a su hijo Alberto (Luis López Somoza) y su esposo Guadalupe (Fernando Soler) (Lincoln Strange Reséndiz, 2019, p. 50).

El resultado, en aras del convencionalismo moral de la época, reinstala a la bondad, el perdón y la abnegación, o sea, los valores tradicionales de la mujer doméstica, como triunfadores.

¿Es Susana una pactante? Al inicio de la trama se desarrolla una escena bastante perturbadora al respecto; salvo problemas de interpretación, dado que la escena en cuestión no revela la sucesión de un pacto diabólico en sí, es posible afirmar que el pacto se sugiere, al menos a manera de un guiño con la apostasía, el trato diabólico implícito, y la presencia contigua del diablo en la vida de los hombres ${ }^{13}$. De acuerdo con los dictámenes demonológicos las entidades infernales siempre están dispuestos a la farsa, la imitación, la parodia y el engaño, por eso fingen prestar ayuda a los desesperados, para alimentar al mal, perder al hombre y contradecir a Dios.

Una Susana airada, casi fuera de sí, reclama a Dios y solicita su ayuda para escapar del encierro. Al parecer, él no responde, quien parece oír sus súplicas es, o un peculiar y sospechoso azar que se tuerce para favorecer al mal, o un demonio invisible para personajes y espectadores. La imagen de la araña negra caminando sobre la silueta de una cruz reflejada sobre el piso de la celda sugiere esta oculta presencia. Así que

\footnotetext{
${ }^{13}$ Según la demonología el pacto puede ser implícito o expreso. Es decir, puede pactase con el mal a través de una invocación informal o mediante un contrato firmado por el pactante y Satanás.
}

la desesperada mujer consigue escapar del encierro, llena de júbilo malsano y de cierta excitación triunfal.

¿Es Susana una persona enferma de sus facultades mentales? Nada indica que el personaje refleje una mente desequilibrada, las alteraciones de su ánimo responden a impulsos externos; la frustración por no conseguir sus objetivos, la rebeldía ante la autoridad, y el oscuro pasado, explican sus acciones. Cuando está tranquila, segura y confiada, sus reacciones son muy naturales, incluso cercanas a la de una persona bondadosa, algo que el mensaje moral y definitivo de la trama sugiere negarle. Doña Carmen, al principio, está convencida de ello al declarar: "Parece tan buena, tan hacendosa, solo lleva dos días aquí y ya se nota su ayuda. Me da pena, porque es tan humilde, tan inocente". Gracias a estos destellos, el personaje gana complejidad, rompe con el estereotipo. Por ejemplo, solicita a los patrones quedarse en la hacienda: “¿Por qué me quiere correr, señor? No he hecho nada y no quiero sino quedarme aquí, donde la vida es buena". Humildad y mansedumbre que traiciona de inmediato al lanzarle una mirada tierna pero sugerente al hacendado. Sus habilidades de manipulación masculina: cediendo ante el asedio del capataz, acosando al ingenuo hijo y seduciendo al confundido padre, dejan clara su inteligencia y su cordura. Puede ser mala, pero no es tonta ni está loca.

Debe ser así, de otro modo, al remitir sus actitudes insidiosas a la locura. Esta explicaría varias facetas de la crisis que desata e incluso justificaría su personalidad y las alteraciones que provoca al entorno familiar y moral, con lo cual el planteamiento ético de la trama disminuiría. A Susana hay que sospecharla fuera de sus cabales, tildarla de loca, temerla, vigilarla, contenerla, amonestarla, incluso llamarla loca, pero solo para auto reconvención y tranquilidad ante amenazas mayores escondidas, en especial de origen infernal, pero el análisis del espectador está obligado a sopesarla cuerda, a fin de que quepa la culpa remitida en el personaje, que sea sujeta a juicio y que la lección sea provechosa. 
¿Es Susana una metáfora del mal? Sí. Pero de acuerdo a un sistema convencional de valores morales que incluye la pasividad, la obediencia, el servicio y la vida familiar como patrones de conducta femenina. Esto no exime al personaje de sus errores, ni mucho menos disculpa las perversas intenciones que pone en juego gracias a su calculadora seducción. Efectivamente es ella quien miente, provoca y conspira para obtener lo que quiere sin importarle el daño a los demás. Es ambiciosa, manipuladora, falaz, hipócrita y perversa, características propias de la maldad humana y preternatural; así que representa al mal, pues encarna y simboliza al peligro del erotismo desbordado, a la ausencia de escrúpulos y a la infamación de los sentimientos. Sin duda, la encarnación por medio de la sensualidad natural de Rosita Quintana, favorece al modelo. La película, mediante escenas de voyerismo y escaramuzas eróticas, sugiere la relación entre el cuerpo y las pulsiones. Deleuze (1984) afirma, justo en su capítulo dedicado a la obra de Buñuel: "Las pulsiones no carecen, ciertamente, de inteligencia: tienen incluso una inteligencia diabólica que hace que cada una elija su parte, espere su momento, suspenda su gesto y adopte los esbozos de forma bajo los cuales podrá cumplir mejor su acto" (p. 180).

Sin embargo, estas mismas características, consideradas nefastas en un sistema moralista, darían como resultado el perfil de una heroína en un contexto ético diferente: su capacidad para adaptarse a entornos nuevos, su tendencia a imponer la voluntad, su ingenio para seducir, su conocimiento de las debilidades humanas, especialmente de las masculinas, más su reticencia ante el trabajo, la autoridad y la disciplina, la convertirían en una gran líder rebelde que está consciente del valor de su cuerpo y del poder de sus atrevimientos. "Susana se libera de las ataduras de su condición social y busca enfrentar a los acosadores a partir de las herramientas con las que cuenta: su sexualidad y su conocimiento de la naturaleza masculina. Susana trata de ganar una batalla” (Lincoln Strange Reséndiz, 2019, p. 56).
A fin de cuentas, ¿quién es Susana? Salvo las posibles explicaciones intrínsecas de la historia contada, es decir, la posibilidad de que sea una huérfana o hija rebelde, según los criterios de la época, a quien, sin remedio, se le confina en un reformatorio - el cual, en lugar de ofrecerle vías de rehabilitación y reinserción social funciona como sistema represor que altera y acrecienta sus resentimientos y perversidades - Susana es una justificación del prejuicio contra las mujeres. La razón moral por la cual la sociedad de mitad del siglo XX afirma preservar la imagen de la mujer tradicional frente a los "peligros" de las mujeres libertinas, hipócritas y seductoras, quienes, ya sea inspiradas por el mal diabólico, o debido a sus propios defectos, alteran, para mal y peor, la deseable armonía de las familias "decentes".

Es fundamental observar que doña Carmen no solo le perdona la ofensa a su esposo, sino que está dispuesta a pelear con Susana hasta sus últimas consecuencias debido a que concibe que este acto le permitirá defender su hogar en todos los sentidos, incluso contra el "demonio". No obstante, después de que Susana sale de la casa, doña Carmen se percata de que la presencia de la joven le permitió reivindicarse como madre y como esposa, además de que le dio la oportunidad de reforzar su rol social; doña Carmen es tan buena madre y esposa, que puede olvidar las humillaciones que ha recibido y se configura a sí misma y ante el espectador como el personaje triunfante (Lincoln Strange Reséndiz, 2019, p. 53).

Es decir, indudablemente, la película contiene redes de convencionalidad moral y social que corresponden al pensamiento conservador de la época, ahí inscrito en contraste; así, el personaje Susana encarna al eje ideológico alrededor del cual se ejemplifican.

La escena final del clímax, más que una moraleja, es una advertencia contra la maldad de las mujeres que no acatan los sistemas domésticos convencionales: toda transgresora será desechada, arrojada a la oscuridad, ajusticiada y encarcelada. 
La impronta de sus acciones debe borrarse y aleccionar a propios y extraños para enfrentar los embates del mal, sea humano o demoniaco.

Desde otro enfoque, hipotéticamente, Susana constituye una dura crítica al sistema patriarcal. Los creadores de la obra ponen en evidencia la endeble estructura de la convivencia rural y sus convicciones morales; como demiurgos sarcásticos insertan una cuña erótica en los ojos de los hombres y en la fe de las mujeres, para demostrar que los convencionalismos familiares y morales bajo los cuales vivimos son o débiles o falsos, pues basta la presencia de una extraña entidad para ponerlos en predicamento. En este caso, Susana sería la herramienta de la cala, un actante que prueba la debilidad de las personas, y que no derrumba toda la formalidad social únicamente debido a su propia identidad de intrusa; tal falta de pertenencia la remite a su entorno original.

Susana (Luis Buñuel, 1950).

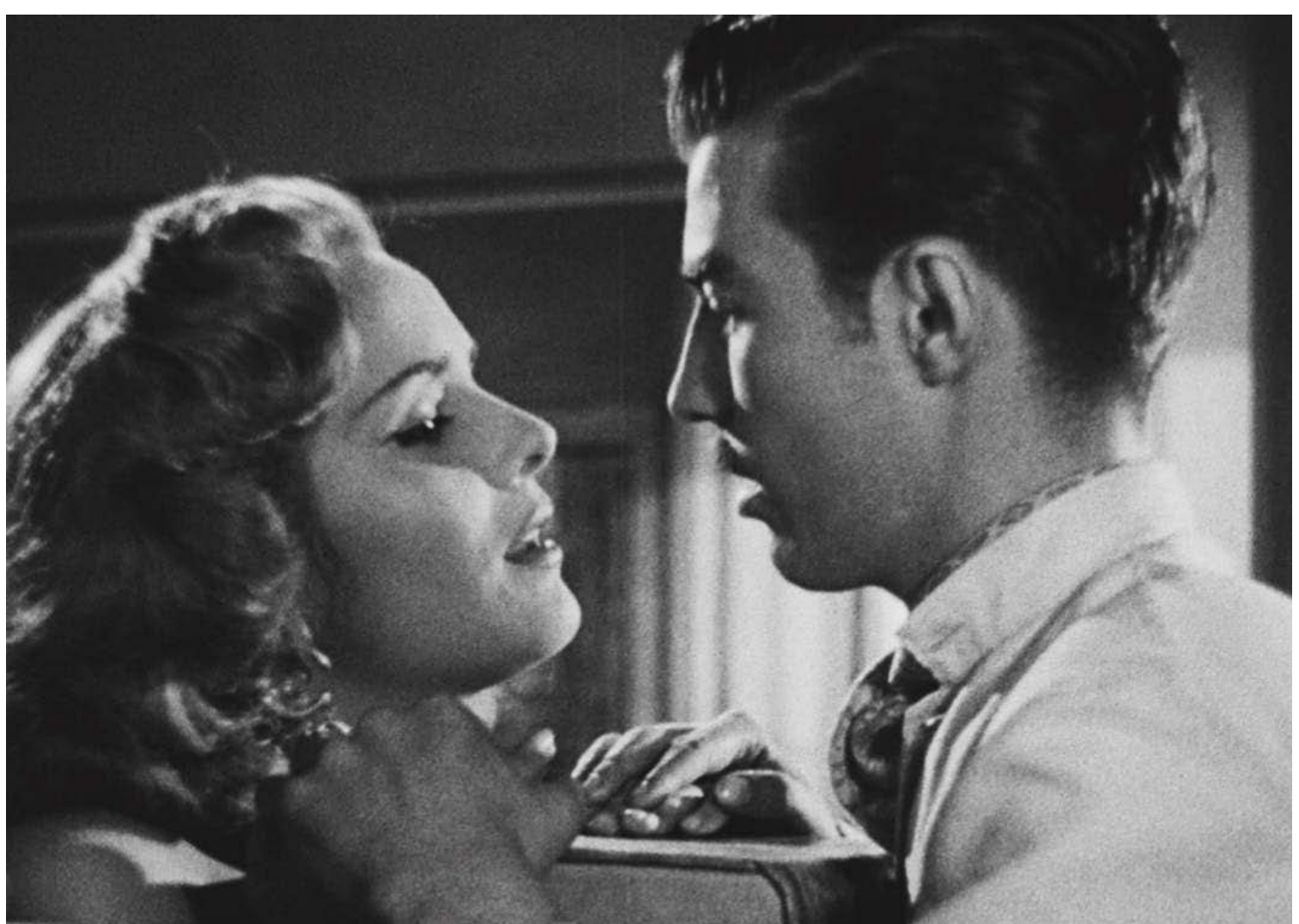




\section{Bibliografía}

\section{Filmografía}

Buñuel, L. (Director) \& Kogan, S. y Reachi, M. (Productores). (1950). Susana.

México: Internacional Cinematográfica.
Deleuze, G. (1984). La imagen-movimiento. Estudios sobre cine 1. Barcelona, España: Paidós.

Díez Ortiz de Uriarte, S. (2010). Luis Buñuel. La subversión ética y estética en su etapa mexicana. En Á. C. Escobar, D. Muñoz Carrobles y R. Peñalta Catalán (Eds.), Exilio: espacios y escrituras. Actas del Congreso Internacional Espacios y escrituras del exilio (pp. 145-154). Madrid, España: Universidad Complutense de Madrid.

Lincoln Strange Reséndiz, I. (2019). Susana (1950) y Viridiana (1961) de Luis Buñuel: personajes y relatos bíblicos. El intercambio dialógico y la carnavalización. El ojo que piensa. Revista de cine iberoamericano, 18, 45-65. doi: https://doi. org/10.32870/elojoquepiensa.v0i18.307

Losilla, G. (1995). A propósito de la mirada buñueliana. Con la excusa de Susana y Belle de jour. Vértigo. Revista de cine, 11, 22-29. Recuperado de http://hdl.handle. net/10251/43022

Martínez Herranz, A. (2007). Susana de Luis Buñuel. Subversión y renovación del melodrama. Latente. Revista de historia y estética del audiovisual, 5, 117-142. Recuperado de http://riull.ull.es/xmlui/handle/915/14341

Martínez Herranz, A. (2008). Susana: de la edad de oro al universo ranchero. Secuencias. Revista de historia del cine, 27, 23-54. Recuperado de https://revistas.uam. es/secuencias/article/view/4061

Ricoeur, P. (1990). Historia y verdad. Madrid, España: Encuentro.

Zamora Calvo, M. J. (Ed.). (2016). Brujas de cine. Madrid, España: Abada. 
Alberto Ortiz (México) es docente investigador del Doctorado en Estudios Novohispanos y la Licenciatura en Letras de la Universidad Autónoma de Zacatecas, México. Miembro del Sistema Nacional de Investigadores y perfil PRODEP. Sus líneas de investigación incluyen propuestas teóricas para analizar la figura del mal en las obras literarias. Como autor ha publicado los siguientes libros alrededor de la tradición mágica en Europa y América: Feijoo y la tradición discursiva en contra de las supersticiones (México, 2006), Tratado de la superstición occidental (Zacatecas, 2009), Diablo novohispano. Discursos contra la superstición y la idolatría en el Nuevo Mundo (Valencia, 2012), El aquelarre. Mito, literatura y maravilla (Barcelona, 2015), El diablo. Interpretaciones del mal figurado según la cultura occidental (México, 2016) y Ficciones del mal. Teoría básica de la demonología literaria para el estudio del personaje maligno (Madrid, 2018). 